\title{
Tunneled Pleural Catheter Drainage
}

National Cancer Institute

\section{Source}

National Cancer Institute. Tunneled Pleural Catheter Drainage. NCI Thesaurus. Code C139568.

A surgical procedure in which a hollow, flexible tube is placed in the thoracic cavity and exits the body through a tunneled path under the skin. 